\title{
SUPERFICIAL ANGIOMYXOMA OF THE NECK WITHOUT ASSOCIATED CARNEY'S COMPLEX: A RARE CASE REPORT
}

Suiyibangbe ${ }^{1}$, Aniruddha Basak ${ }^{2}$, Keisham Lokendra Singh ${ }^{3}$, S. Ranita Devi ${ }^{4}$, G. S. Moirangthem ${ }^{5}$

\section{HOW TO CITE THIS ARTICLE:}

Suiyibangbe, Aniruddha Basak, Keisham Lokendra Singh, S. Ranita Devi, G. S. Moirangthem. "Superficial Angiomyxoma of The Neck without Associated Carney's Complex: A Rare Case Report". Journal of Evolution of Medical and Dental Sciences 2015; Vol. 4, Issue 43, May 28; Page: 7559-7562, DOI:10.14260/jemds/2015/1097

ABSTRACT: Superficial angiomyxomas are rare benign soft tissue tumour usually solitary and predominantly involving the dermis and subcutis. We report a case of 21 years old male who presented with a history of swelling on the left upper anterolateral aspect of neck, measuring $3 \times 2 \mathrm{~cm}$ with irregular surface, non-tender, mobile and firm in consistency, fixed to the skin but not to the underlying structured. No lymph node was palpable. There was no evidence of any of the components of Carney's complex at the time of presentation. Provisional diagnosis was made as Pleomorphic adenoma by FNAC. Wide local surgical excision was done. Histopathology examination revealed to be superficial angiomyxoma. Here, we present a case of superficial angiomyxoma with a review to its rarity and difficulty in diagnosing and distinguishing from other soft tissue tumour of the skin.

KEYWORDS: Solitary, Superficial angiomyxoma, cutaneous myxoma.

INTRODUCTION: Superficial angiomyxoma is a rare benign tumour of dermis and subcutis which was first described by Carney and colleagues in 1986 as a cutaneous myxoma of carney's complex.[1] Later, in 1988 Allen et al[2] described as a cutaneous tumour histologically similar to cutaneous myxoma but without associated with carney's complex. This benign tumor can occur as a solitary or multiple nodule or polypoid lesion. They can occur in various sites like in trunk, limbs, neck and perineal region. ${ }^{[3]}$ They usually presents in middle aged adults with slight male preponderance. ${ }^{[4]}$ Superficial angiomyxoma should be distinguished from other cutaneous myxoidtumour due to its local recurrence. In the present study, the patient was diagnosed to be having a solitary cutaneous angiomyxoma in the left upper anterolateral aspect of the neck based on histopathological report following wide local excision and without any recurrence after follow up for six months.

CASE REPORT: A 21 years old male presented with a painless soft tissue swelling on the left upper anterolateral aspect of the neck, the swelling was sudden in onset and gradually increases in size and painless with duration of four month. There was no history of trauma at the site. Physical examination revealed a single mass with irregular surface, non-tender, mobile and firm in consistency measuring $3 \times 2 \mathrm{~cm}$. No lymph node was palpable. No other similar lesions were seen elsewhere. Local radiograph was unremarkable. Ultrasonography revealed, oval shaped, hypoechoic lesion in the subcutaneous and cutaneous plane. FNAC revealed pauci-cellular smear shows predominance of stromal fragment in the form of mark fibrillarychondromyxoid ground substances along with few epithelial cells arranged loosely cohesive cluster which are round to oval shaped bearing abundant well defined cytoplasm with fine evenly textured chromatin. Based on FNAC report diagnosis of Pleomorphic adenoma was made. Routine pre-operative investigations were within ormal limits. Wide local excision was performed under general anaesthesia. Tumor mass was removed and sent for histopathological examination. 


\section{CASE REPORT}

Gross Pathology: Specimen consists of a single grey-white skin tissue fragment measuring $3.5 \times 2.5 \times 2 \mathrm{~cm}$. Cut surface was gelatinous, glistening, slimy, homogenous, greyish white, solid with some cystic areas.

Microscopy: Section studied show skin with dermis displaying an un encapsulated relatively well circumscribed tumour composed of slit like blood vessels line by flattened endothelium in a fibromyxoid stromal background, many areas show pools of myxoid material and note is made of dilated lymphatic channels. Deeper areas also show bundles of smooth muscle (Fig. 3). The surgical resected margins are free of the tumour. Histological diagnosis of cutaneous Angiomyxoma was given.

DISCUSSION: Superficial angiomyxoma (Cutaneous myxoma) is a benign soft tissue tumor which was first described by Carney and colleagues in 1986. Later in 1988 by Allen et al.

Calonje et al in 1999, described cutaneous myxoma as a distinctive entity but poorly recognized cutaneous tumors with tendency for recurrence.[5]

Cutaneous angiomyxoma is to be differentially diagnosed and distinguished from other myxoidtumour including benign and low grade malignant myxoid lesions like aggressive angiomyxoma, focal cutaneous mucinosis, myxoidneurothekeomas, myxoidneurofibroma, superficial acralfibromyxoma and myxoidliposarcoma.

Superficial angiomyxoma is a rare benign tumor with a tendency of local recurrence. This tumour is usually non distructive and never metastasizes. Local resection with wide margins is the main stay of treatment in all cases. Local radiotherapy can be done for recurrent cases or margin positive cases. Radiotherapy and hormonal therapy is not fully established. Wide local excision with tumour margin free is the treatment of stay.

Allen et al reported 30 SA's in 28 patients (16 male and 12 female patients) whose ages ranged from 4 to 78 years (mean, 39 years). Tumor size varied from 0.5 to $9 \mathrm{~cm}$, with the majority measuring 1 to $5 \mathrm{~cm}$. Eleven tumors (37\%) were located on the trunk, 10(33\%) on the lower extremity, $5(17 \%)$ on the head or neck, and $4(13 \%)$ on the arm. ${ }^{[2]}$ Rare congenital examples have been described. These lesions can occur anywhere but there is a predilection for the trunk, lower extremities, head and neck. Some even arises in the genital region of both males and females (vulva, mons pubis, scrotum, inguinal region).

When the lesion is associated with Carney's complex (i.e., Cutaneous myxomas, cardiac myxomas, spotty pigmentation and endocrine over activity), they are often multiple and frequently occur in the eyelid or externalear.[6,7]

Cutaneous myxoma are mostly solitary lesion with varying sizes. Grossly, they are usually well circumscribed tumors with a gray white glistening gelatinous on cut surface. Thin fibrous septa traverse the neoplasm. Cysts that are sometimes filled with keratinous debris may be identified grossly. ${ }^{[8]}$ Histologically, this lesion has a lobular or multinodular appearance at low magnification. Histologically poorly circumscribed with extension into the underlying subcutaneous tissue and rarely skeletal muscle. Myxoidstroma are alcian blue positive, hyaluronidase sensitive and may have acellularmucin pools with scattered bland stellate and spindled cells. Occasional multinucleated cells and pleomorphism. Mitotic figures are rare. Occasional intranuclearpseudo inclusions. Characteristically many thin-walled small blood vessels with frequent neutrophils infiltrate and entrapped epithelial component in $20-30 \%$ of cases as Keratinous cyst, Thin strands of squamous epithelium and Basaloid buds. 
Aggressive angiomyxoma is a benign tumour but has infiltrative potential into skeletal muscle and fat. They usually tend to grow larger and involve deeper structures, Medium to large thick walled vessels with desmin positive and no stromal neutrophils. Usually occur in perineum and female genitelia. In Superficial Acral Fibromyxoma, neutrophils and Epithelial component are rare but with Prominent fibrous component mixed/alternating with moderately cellular myxoid areas and EMA variably positive. They arise on the fingers and toes of middle aged adult.[10]

CONCLUSION: A rare case of superficial angiomyxoma of neck without associated carney's complex in a 21 years old male patient. The pre-operative finding FNAC finding revealed Pleomorphic Adenoma thought the site is unusual. Post-operative histopathology revealed superficial Angiomyxoma which is a very rare benign tumour that can occur in head and neck, trunk and lower extremity. It is worthwhile to keep in mind this type of lesion as one of the differential diagnosis for any benign skin tumour.

\section{REFERENCES:}

1. Carney JA, Gordon H. Carpenter PC, et al. The complex of myxomas, spotty pigmentation, and endocrine overactivity. Medicine (Baltimore) 1985: 64-270.

2. Allen PW, Dymock RB, Mac Cormac LB. Superficial angiomyxomas with or without epithelial components. Report of 30 tumors in 28 patients. Am J Surg Pathol, 1988: 12 (7): 519-530.

3. Fetsch JF, Laskin MB, Tavassoli FA. Superficial angiomyxoma 9Cutaneous myxoma0; Aclinicopathologic study of 17 cases arising in the genital region. Int J Gynecol Pathol 1997; 26: 325.

4. Bedlow AJ, Sampson SA, Holden CA. Congenital superficial angiomyxoma. Clin Exp Dermatol 1997; 22: 237.

5. Calonje E, Guerin D, McCormick D, Fletcher CD. Super ficiaangiomyxoma. Clinicopathologic analysis of a series of distinctive but poorly recognized cutaneous tumors with tendency for recurrence. Am J Surg Pathol 1999 Aug; 23 (8): 910-917.

6. Ferreiro JA, Carney JA. Myxomas of external ear and their significance. Am J Surg Pathol 1994, 18 (3): 274-280.

7. Yuen HK, Cheuk W, Luk FO, Wat CS, Auyeung KC, Lam DS. Solitary Superficial angiomyxoma in the eyelid. Am J Opthalmol 2005 Jun; 139 (6): 1141-1142.

8. Takahashi H, Hida T. Corney complex: Report of a Japanese case associated with cutaneous superficial angiomyxomas, labial lentigines, and a pituitary adenoma. J Dermatol 2002 Dec; 29 (12): 790-6.

9. Wilk M, Schmoeckel C, Kaiser HW, Hepple R, Kreysel HW. Cutaneous angiomyxoma: a benign neoplasm distinct from cutaneous focal mucinosis. J Am Aead Dermatol 1995 Aug; 33 (2pt2): 352-5.

10. Fetsch JF, Laskin MB, Miettinen M. Superficial acralfibromyxoma: A clinicopathologic and immunohistochemical analysis of 37 cases of a distinctive soft tissue tumors with a predilection fingers and toes. 2001 Jul; 32 (7): 704-714. 


\section{CASE REPORT}

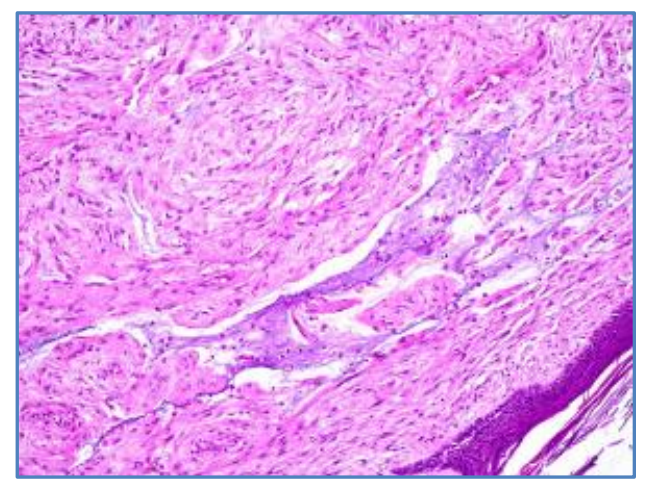

Fig. 1: HPE

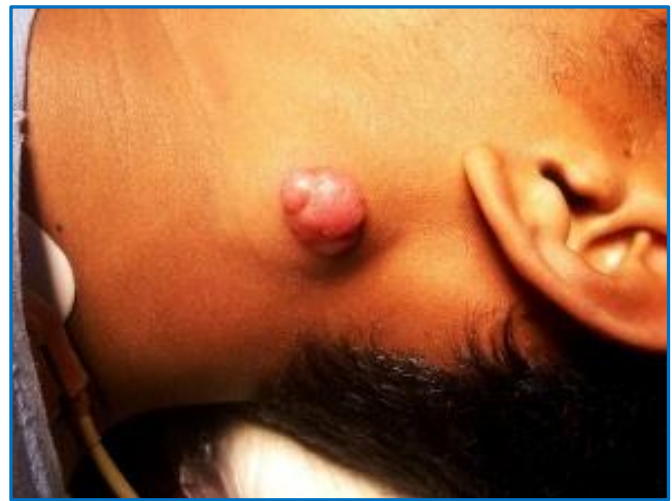

Fig. 2: Pre OP

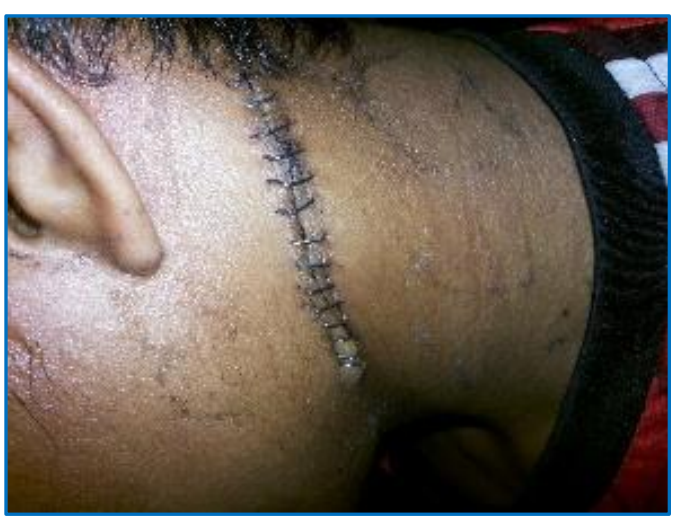

Fig. 3: Post OP

\section{AUTHORS:}

1. Suiyibangbe

2. Aniruddha Basak

3. Keisham Lokendra Singh

4. S. Ranita Devi

5. G. S. Moirangthem

\section{PARTICULARS OF CONTRIBUTORS:}

1. Post Graduate Trainee, Department of Surgery, Regional Institute of Medical Sciences, Imphal, Manipur.

2. Post Graduate Trainee, Department of Surgery, Regional Institute of Medical Sciences, Imphal, Manipur.

3. Senior Resident, Department of Surgery, Regional Institute of Medical Sciences, Imphal, Manipur.

\section{FINANCIAL OR OTHER} COMPETING INTERESTS: None
4. Professor, Department of Surgery, Regional Institute of Medical Sciences, Imphal, Manipur.

5. Professor \& HOD, Department of Surgery, GI \& MAS Regional Institute of Medical Sciences, Imphal, Manipur.

\section{NAME ADDRESS EMAIL ID OF THE CORRESPONDING AUTHOR:}

Dr. Suiyibangbe,

Post Graduate,

Hostel No.1, Room No. 22,

RIMS Imphal-797002, Manipur.

E-mail: sui_zet@yahoo.co.in

Date of Submission: 08/05/2015.

Date of Peer Review: 12/05/2015.

Date of Acceptance: 22/05/2015.

Date of Publishing: 28/05/2015. 